\title{
Qualitative Classification of the La Nina Events
}

\author{
E.N. Voskresenskaya, O.V. Marchukova \\ Marine Hydrophysical Institute, Russian Academy of Sciences, Sevastopol, \\ Russian Federation \\ e-mail: elena_voskr@mail.ru, olesjath@mail.ru
}

\begin{abstract}
La Nina is a cold episode of the El Nino Southern Oscillation (ENSO) phenomenon which is the strongest climatic signal on the inter-annual time scale; besides it greatly affects the world population. It plays an important role in formation of climate and environment anomalies. Based on the global HadISST datasets on sea surface temperature in the Nino3.4 region of the equatorial Pacific in 1870 - 2013 and the South Oscillation index (SOI) data, the La Nina events are selected and described. The obtained results are used as a ground for classifying the La Nina events. Taking into account typical variability of three main characteristics, i.e. intensity, duration and maximum SOI level, three types of the La Nina events are selected using the objective cluster analysis method. Three types of the La Niña events are distinguished by the objective classification. Type I is characterized by maximum duration (more than two years) and the highest intensity, type II - less pronounced features: moderately weak intensity and mid duration, and type III - low intensive and low- or midenduring La Nina events with low values of the Southern Oscillation index. Quasiperiodicity, apparently, conditioned by low-frequency variability in the ocean-atmosphere system is characteristic of the anomalies' temporal variation corresponding to each of the distinguished types.
\end{abstract}

Keywords: La Niña, El Niño - South Oscillation (ENSO), South Oscillation index, Pacific Ocean region.

DOI: 10.22449/1573-160X-2015-3-14-24

(C) 2015, E.N. Voskresenskaya, O.V. Marchukova

(C) 2015, Physical Oceanography

Introduction. The El Niño - South Oscillation (ENSO) phenomenon is the most important climatic signal of the inter-annual scale producing a significant impact on the environment [1]. ENSO includes warm (El Niño) and cold (La Niña) episodes the quasi-period of which is $2-7$ years [2]. The El Niño events are investigated in numerous papers which provide not only a general characteristic of the events, but also contain the attempts to classify them [2, 3]. However, up to now the study of the La Niña events, particularly, the problem of their classification has been paid much less attention.

Brief characteristic of La Niña implies that this term denotes the event accompanied by abnormal temperature decrease in the surface layer of the equatorial Pacific Ocean. At that the researchers of this phenomenon usually emphasize that the matter concerns the extreme water cooling [4]. In contrast to El Niño, at present there is no a universal definition of La Niña. Each scientific institution proposes its own criteria according to which they distinguish and itemize the events. Moreover, until the end of the 1990s La Niña was not considered as an individual process, but as a result of the El Niño development [5]. Only after the information on negative social consequences of La Niña in 1998 2000 became widely known due to media, scientists began to study these events more closely [4].

At the summit in Boulder (USA, Colorado) devoted to La Niña, it was noted for the first time that intensity of these phenomena can be weak, moderate, strong, very strong, and even extremely strong [5]; and just the La Niña intensity level conditions the environmental and economic consequences. But speaking about 
moderate and strong events, nobody takes into account duration of these events. Just after the La Niña in 1998 - 2000 when the cold anomaly of the sea surface temperature (SST) lasted from July, 1998 to June, 2000, for the first time the concept of a two-year La Niña occurred [5]. At the same time some authors, for example in [2], who studied the characteristics of different types of the La Niña and El Niño events based on SST and the ocean surface salinity (OSS), described the La Niña event in 1998 - 2000 as a sequence of two events: in $1998-1999$ and in 1999 - 2000. The first event was typed as the Central Pacific one, and the second - as the East Pacific. Such an ambiguity of information, as a rule, hampers its application for solving the applied and management tasks of regional development. Therefore there arose a necessity in more comprehensive studying of the La Niña events with the purpose of their classification which takes into account their intensity and duration, and also the phases both of the La Niña maximum intensity and the highest value of the South Oscillation (SO) index during the evolution of the very event. The present paper is devoted just to such a research.

Data and methods. The global data on the SST monthly average values for $1870-2013$ for the Nino3.4 region $\left(5^{\circ} \mathrm{N}-5^{\circ} \mathrm{S}\right.$ and $\left.170-120^{\circ} \mathrm{W}\right)$ calculated using the global data array HadISST (Met Office Hadley) were used for analysis [6]. The indicated array was chosen based on analyzing the results of test calculations carried out in [2] due to two widely used at present SST data arrays (HadISST and ERSST). The authors demonstrated both the advantages and the drawbacks of the compared arrays and showed that a set of the HadISST data array was more preferable for studying the SST inter-annual variability and for classifying temperature anomalies in the equatorial Pacific. Besides, the analysis was supplemented with the data on the SO index for 1856 - 2013 calculated by the scientists of the Climatic Research Department, University of the Eastern England, using the method described in [7]. The SO index represents a difference between the normalized values of surface pressure in two points in the Pacific Ocean: the Port Darwin and the Tahiti Island. The series of the obtained data were tested to define correspondence of the distribution empirical function (DEF) to the normal law. The curves represented in Fig. 1 confirm that DEF distributions correspond to the normal distribution law as the statistical criterion $\chi^{2}$ is smaller than the critical one $\chi_{\mathrm{cr}}^{2}(16.2<22.4$ (Fig. 1, a) and $16.1<22.4$ (Fig. 1, b) ). This statistical conclusion provides the grounds to assume that the selected data series are suitable for further analysis.

To classify the La Niña event, the cluster analysis method was chosen. As a rule, three approaches are selected in the theory of mathematical classification: discrimination (discriminant analysis), clustering (cluster analysis) and grouping [8]. At that the aim of clustering is to reveal and distinguish the classes. The task of the cluster analysis consists in defining (using the empirical data) to what extent the elements group or disintegrate into the isolated clusters. In other words, the task of the cluster analysis is to reveal natural division (free of the researcher subjective view) into the classes. Its ultimate goal is to select the groups of homogeneous objects similar to each other at simultaneous drastic difference of these groups from each other [9]. The cluster analysis permits to considered rather large information contents, reduce them strongly transforming into a compact and illustrative form [10]. In the present paper the authors used one of the types of a cluster analysis - the hierarchical one. Its essence consists in successive uniting the clusters, or in dividing the large clusters into the small ones; the Euclidean distance is chosen to be a link measure between them.

PHYSICAL OCEANOGRAPHY NO. 3 (2015) 

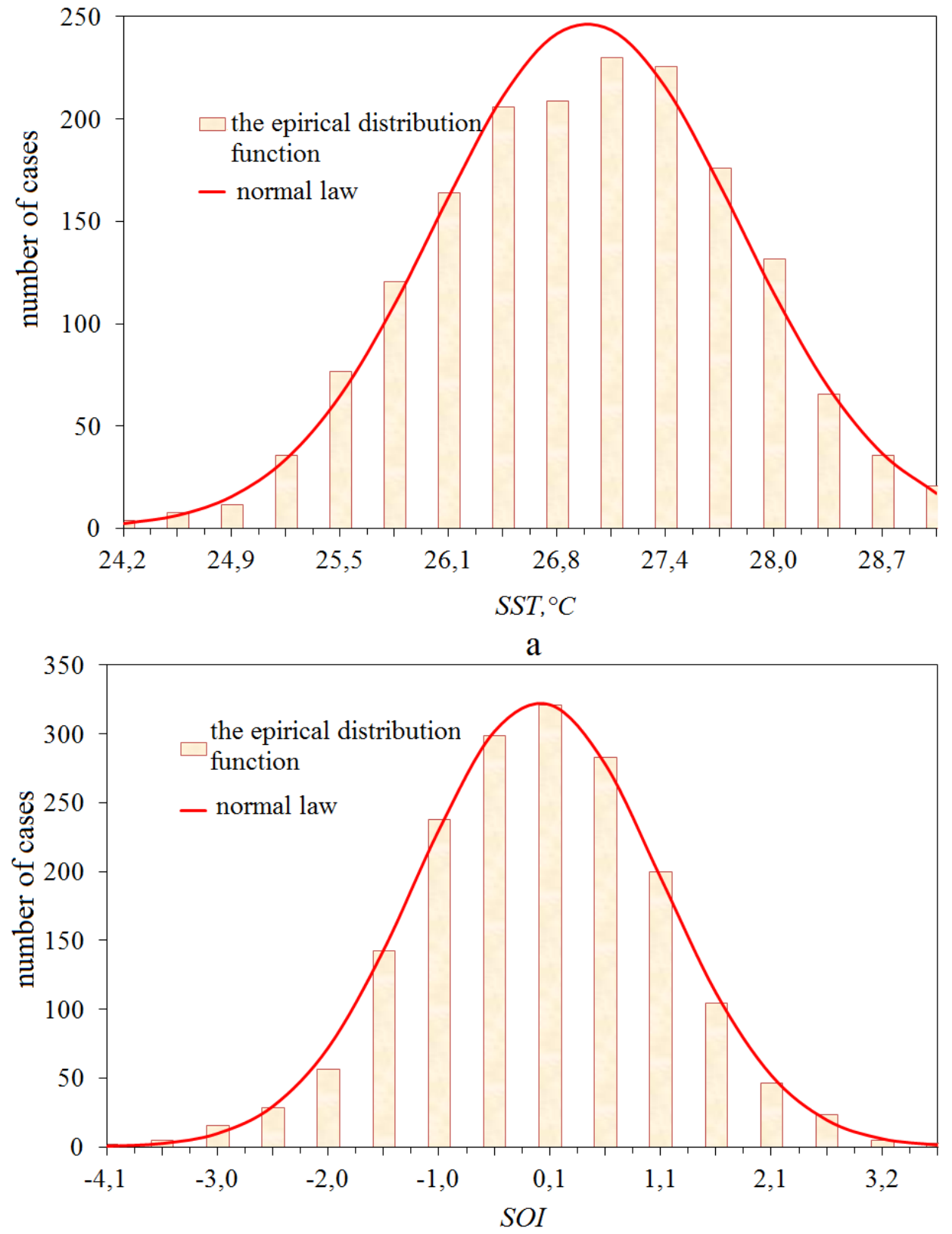

$\mathrm{b}$

Fig. 1. Empirical function and the corresponding normal law of distribution of the SST monthly average values in the Nino3.4 region for $1870-2013(a)$ and the SO index values for $1856-2013(b)$

Results of the analysis. By the analogy with El Niño, La Niña is usually characterized by the corresponding index of the event. One of such indices is the widely used Nino3.4 [11] which represents the SST monthly average anomaly in the equatorial Pacific Ocean ( $5^{\circ} \mathrm{N}-5^{\circ} \mathrm{S}$ and $170-120^{\circ} \mathrm{W}$ ) (Fig. 2). It is 
determined in the National Ocean and Atmosphere Administration (NOAA) that the La Niña event means adoption of the conditions at which the Nino3.4 index value lower than $-0.5{ }^{\circ} \mathrm{C}$ remains during the period not shorter than five subsequent months [12]. The threshold value for each series of the SST indices depends on the value of its rms deviation (RMSD) in the Nino3.4 region [11]. To define the $L a$ Niña events, the authors of the paper, resting on the RMSD assessment of a data series analyzed using SST, have selected the criterion at which the threshold value was $-0.48{ }^{\circ} \mathrm{C}$, and the minimum duration was 4 months, provided that the natural anomaly value would not be smaller than RMSD of the whole series (where $\sigma=$ $=0.88^{\circ} \mathrm{C}$ ).

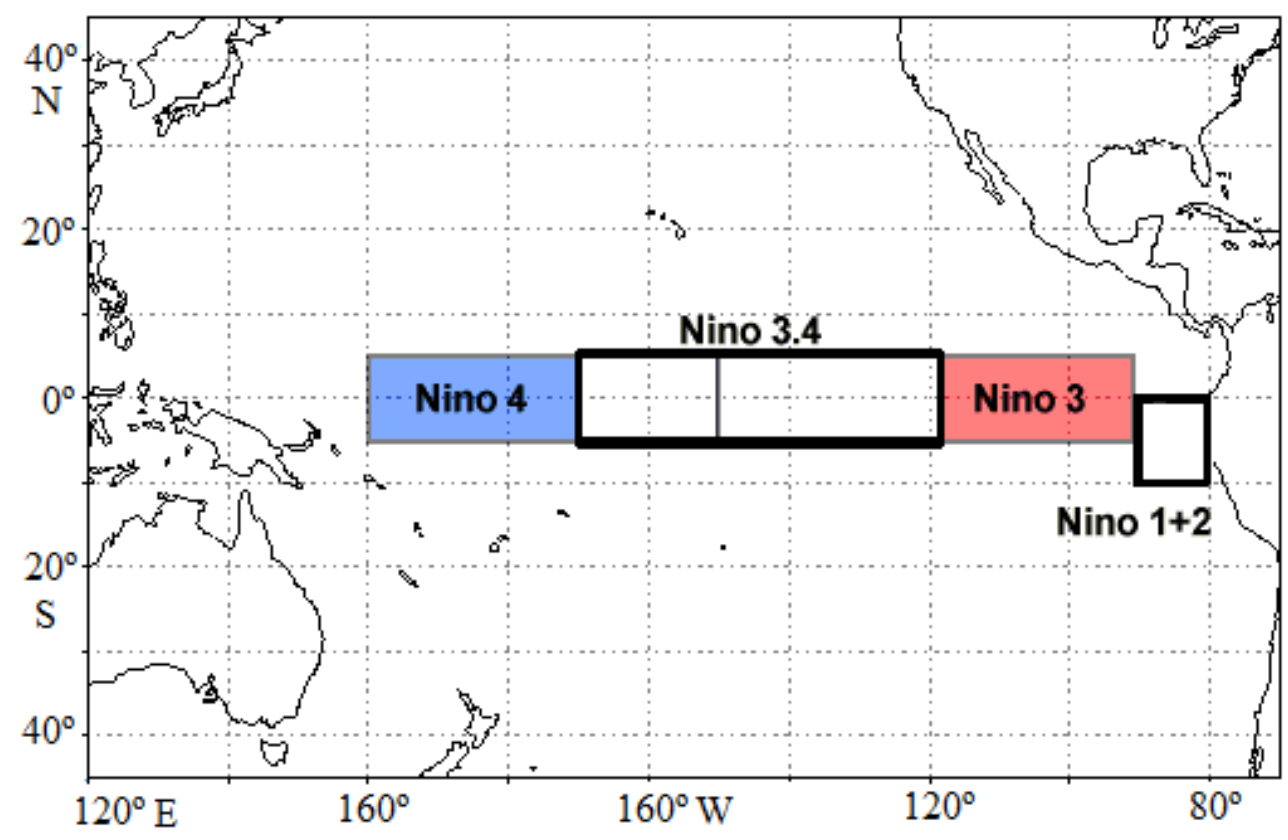

Fig. 2. The Pacific Ocean regions for which the temperature indices of the ENSO events are calculated

Thus, application of the above criterion permitted to distinguish 32 events of La Niña from the data array for 143 years. Fig. 3 represents the graphs of the SST temporal variation by 20-year intervals. Note that the other authors, for example in $[2,3,11]$, have also selected such events, but they used mainly the data starting from 1950. Our results obtained for these 63 years are in good agreement with their results. In our study the above-mentioned period contains 16 events. The information from the NOAA official website is given as an example: scientists of this institution have distinguished 17 La Niña events which occurred in course of this period. 

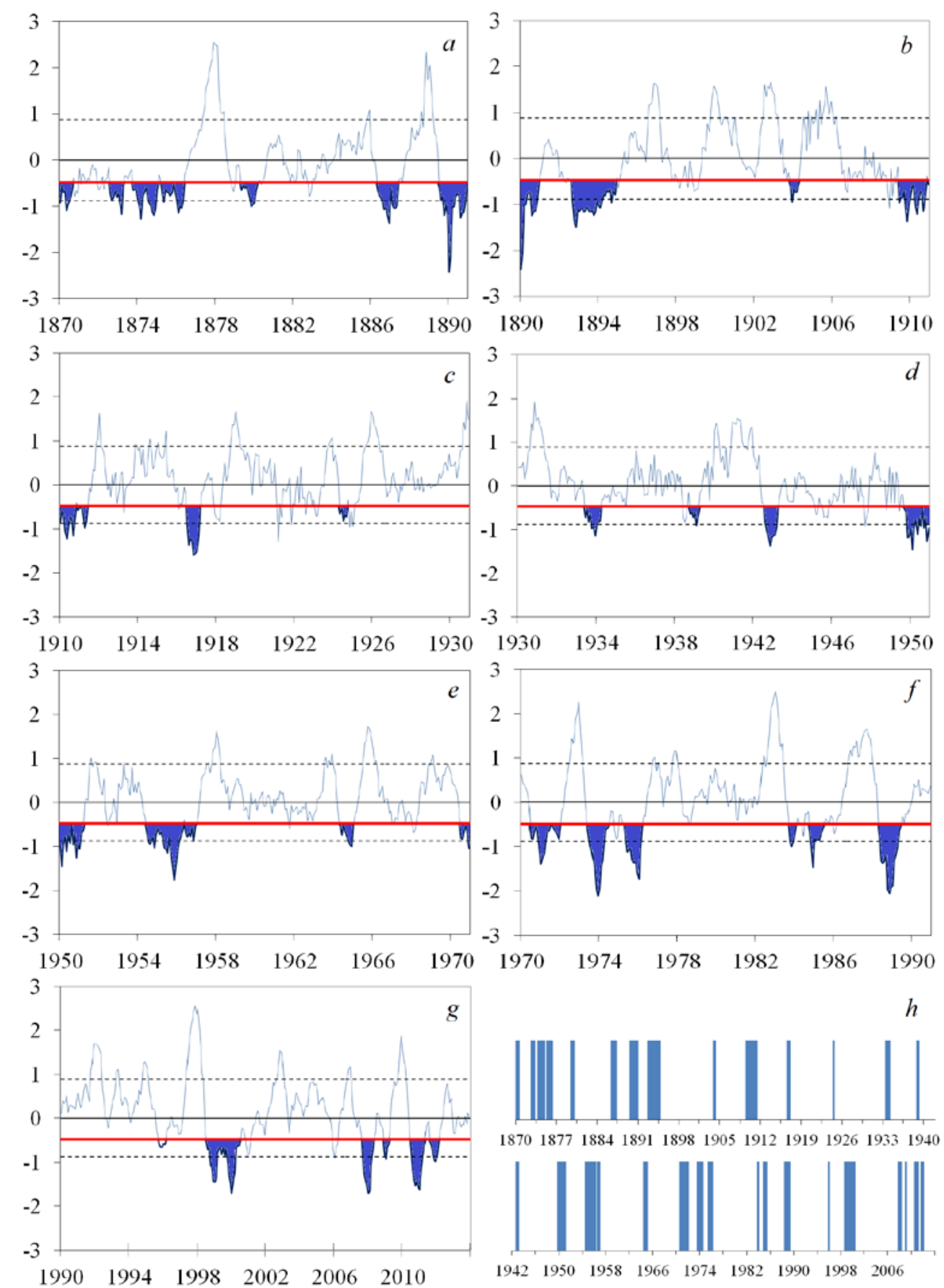

Fig. 3. Normalized variation of the Nino3.4 index values for $1870-1890(a), 1890-1910(b)$, $1910-1930(c), 1930-1950(d), 1950-1970(e), 1970$ - $1990(f), 1990-2013(g)$ (filing denotes the La Niña events, bold line marks the threshold $-0.48^{\circ} \mathrm{C}$, dashed lines show the index RMSD) and the histogram of the events recurrence $(i)$ 
The discrepancy constituted only one event in 2005 - 2006 for which the phase of the event start was not defined accurately enough. This is explained by the fact that the techniques for distinguishing the La Niña events, the values of the Nino3.4 index threshold and also the data arrays were used for analysis were different. In our study it is the array HadISST, in the NOAA case - ERSST. In article [3], 14 events in 1950 - 2011 were revealed that was in a good agreement with the results of the present study; however the phases of beginning and duration of the very phenomena did not always coincide. This inconsistency stems from the fact that in order to distinguish the La Niña events, the authors of [3], instead of the Nino3.4 index, used two individual normalized indices: Nino3 and Nino4.

To obtain the generalized description of the selected La Niña events, duration ( $\Pi$, month), intensity $\left(И,{ }^{\circ} \mathrm{C}\right)$, the maximum intensity phase ( $\Phi_{\mathrm{U}}^{\max }$, months) and the SO index maximum value during the evolution of the very phenomenon were calculated for each event. The recalculation results are given in the Table. At that significant differences in the values of each parameter draw special attention. The La Niña intensity level is characterized by the value of the SST anomaly minimum during the event existence. In the obtained estimates, the intensity value varies from $-2.4^{\circ} \mathrm{C}(1889-1890)$ to $-0.7^{\circ} \mathrm{C}(1995-1996)$. Minimum duration of the event is 4 months (1983 - 1984 and 2008 - 2009) and maximum one - 28 months (1892 - 1894). The maximum values of the SO index during the La Niña evolution vary between $0.34-3.36$. At that the highest intensity of the La Niña events is achieved in November. The La Niña contribution to the total dispersion of the SST monthly average variability in the Nino3.4 region for the complete series from 1870 to 2013 constituted $48.5 \%$. At the same time, even the visual analysis of the values of the La Niña characteristics listed in the Table shows that the considered events can be united into the groups. At the preliminary stage of study it was done based on the subjective features of each characteristic; and thus the following classification was obtained.

Proceeding from their intensity the La Niña events were divided into four types: weak (at which the anomalies' value is from -0.7 to $-0.9^{\circ} \mathrm{C}$ ), moderate (from -1.0 to $-1.6^{\circ} \mathrm{C}$ ), strong (from -1.7 to $-1.9^{\circ} \mathrm{C}$ ) and very strong $\left(-2.0^{\circ} \mathrm{C}\right.$ and higher). The examples of very strong La Niña events are those that took place in 1889 1890, 1973 - 1974, 1988 - 1989, and the examples of the weak ones distinguished only at presetting the threshold value are the events in 1924, 1938 - 1939, 1956 1957, 1995 - 1996 and 2008 - 2009. Note that the subjective classification of the El Niño events based on intensity [13] showed presence of three types of events (weak, moderate and strong) that was further confirmed by the cluster analysis.

Classification of La Niña by its duration permitted to distinguish four types of events: short ( $4-6$ months), middle (7 - 12 months), long (13 - 23 months) and the most prolong ones (24 months or more). The most prolong La Niña is represented by only two events: in $1892-1894$ (28 months) and in $1998-2000$ (24 months). It is noteworthy that the characteristics of the both events are such that they can not be attributed to very strong La Niña. The performed subjective classification has no mathematical basis, and it only helps to consider the La Niña events' basic characteristics. Therefore, the paper represents the objective classification carried out by the cluster analysis. 
The La Niña events and their characteristics in the Nino3.4 region in 1870 - 2013 according to the HadISST data array

\begin{tabular}{|c|c|c|c|c|}
\hline $\begin{array}{l}\text { La Niña } \\
\text { events, year }\end{array}$ & Duration, month & Intensity, ${ }^{\circ} \mathrm{C}$ & $\begin{array}{l}\text { Maximum } \\
\text { intensity } \\
\text { phase, month }\end{array}$ & $\begin{array}{l}\text { Maximum } \\
\text { value of the } \\
\text { SO index }\end{array}$ \\
\hline 1870 & 8 & -1.1 & 5 & 1.06 \\
\hline $1872-1873$ & 9 & -1.2 & 3 & 3.14 \\
\hline 1873-1875 & 16 & -1.3 & 11 & 2.19 \\
\hline 1875-1876 & 14 & -1.1 & 2 & 2.57 \\
\hline 1879-1880 & 10 & -1.0 & 11 & 2.20 \\
\hline 1886-1887 & 13 & -1.4 & 12 & 1.51 \\
\hline 1889-1890 & 18 & -2.4 & 1 & 2.35 \\
\hline 1892-1894 & 28 & -1.5 & 11 & 2.15 \\
\hline 1903-1904 & 6 & -1.0 & 12 & 3.64 \\
\hline 1909-1910 & 17 & -1.4 & 11 & 2.63 \\
\hline 1910-1911 & 7 & -1.0 & 4 & 1.66 \\
\hline 1916-1917 & 9 & -1.6 & 11 & 2.57 \\
\hline 1924 & 5 & -0.8 & 7 & 1.19 \\
\hline 1933-1934 & 10 & -1.1 & 12 & 0.81 \\
\hline 1938-1939 & 6 & -0.9 & 2 & 1.74 \\
\hline 1942-1943 & 8 & -1.4 & 11 & 1.42 \\
\hline 1949-1951 & 19 & -1.3 & 11 & 3.06 \\
\hline 1954-1956 & 19 & -1.8 & 11 & 1.80 \\
\hline 1956-1957 & 8 & -0.9 & 11 & 1.92 \\
\hline 1964-1965 & 9 & -1.0 & 12 & 1.32 \\
\hline 1970-1972 & 19 & -1.4 & 1 & 2.58 \\
\hline 1973-1974 & 14 & -2.1 & 12 & 2.85 \\
\hline 1975-1976 & 11 & -1.7 & 1 & 2.15 \\
\hline 1983-1984 & 4 & -1.0 & 11 & 0.34 \\
\hline 1984-1985 & 9 & -1.5 & 12 & 1.42 \\
\hline 1988-1989 & 14 & -2.0 & 11 & 2.18 \\
\hline 1995-1996 & 5 & -0.7 & 12 & 0.82 \\
\hline 1998-2000 & 24 & -1.7 & 1 & 2.10 \\
\hline 2007-2008 & 8 & -1.7 & 1 & 2.05 \\
\hline 2008-2009 & 4 & -0.9 & 1 & 1.43 \\
\hline 2010-2011 & 10 & -1.6 & 1 & 3.02 \\
\hline 2011-2012 & 7 & -1.0 & 12 & 2.45 \\
\hline
\end{tabular}

The hierarchical method was applied to classify the La Niña events. The Euclidean distance was chosen to be the measure of the objects' proximity. It is the most often used metrics in the cluster analysis representing a geometric distance in a multi-dimensional space [10]. The La Niña events were clustered with due account of various characteristics. Two parameters were selected in 
course of the first experiment: intensity and duration. Clustering by these parameters yielded two well pronounced clusters that clearly divided the events into two types. The first type includes 18 moderately weak and low- or midenduring events $\left(\mathrm{I}=\left[\begin{array}{lll}-0.7 & \ldots & -1.1^{\circ} \mathrm{C}\end{array}\right] ; \mathrm{P}=\left[\begin{array}{llll}4 & \ldots & 10 \text { months }\end{array}\right)\right.$. The second type including 14 La Niña events is characterized by moderately strong and mid- or long-enduring phenomena $\left(\mathrm{I}=\left[\begin{array}{lll}-11 & \ldots & -24^{\circ} \mathrm{C}\end{array}\right]\right.$; $\mathrm{D}=\left[\begin{array}{ll}8 & \text { months or more }\end{array}\right)$. The second and the third experiments on clustering the La Niña events were held in view of two more characteristics: the phase of the La Niña maximum development and the highest value of the SO index during the period of the very event. Clustering in the third experiment performed with consideration of all four characteristics did not give a satisfactory result. Besides, dividing of the events into two clusters showed that there were no distinct differences between them. Therefore the authors took a decision in favor of the second experiment which allowed for the La Niña intensity and duration, and also the maximum value of the SO index.

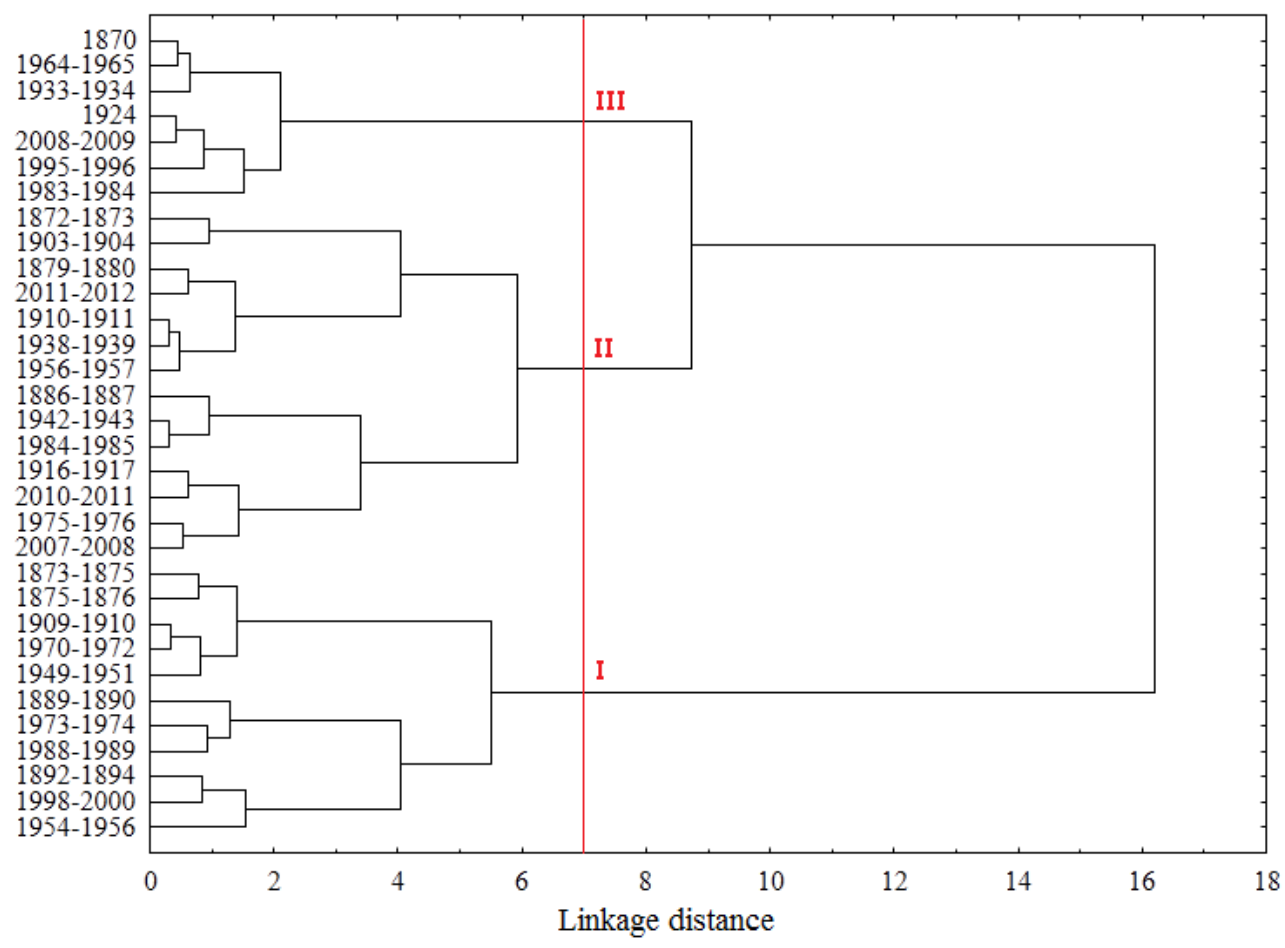

Fig. 4. Classification of the La Niña events for 1870 - 2013 by the cluster analysis method based on three basic characteristics (event intensity, its duration and maximum value of the SO index)

The La Niña events' dendogram is shown in Fig. 4. Three clusters are well seen; it permits to speak more precisely about availability of the La Niña three types allowing for the features of the above-mentioned basic characteristics. The first cluster (type I) included 11 La Niña events, the following conditions corresponded to it: $\mathrm{I}=\left[1.1 \ldots-2.4^{\circ} \mathrm{C}\right], \mathrm{D}=[9-28$ months $]$, SO index $=[1.8-$ 3.14]. The characteristic features of the events of this type are the maximum 
duration exceeding two years (1892 - 1894, 1998 - 2000), and significant intensity resulting, as a rule, in strong climatic anomalies [5] (1889 - 1890, 1973 - 1974, 1988 - 1989). Type II (14 events) is characterized by insufficiently clear distinctions since the extreme values' limits of the governing parameters can be attributed to the types I and III. The limits' values of this type characteristics are: $\mathrm{I}=\left[-0.9 \ldots-1.7^{\circ} \mathrm{C}\right], \mathrm{D}=[7-16$ months $]$, SO index $=[1.42-3.64]$. This group includes the event in 1903 - 1904 with the maximum SO index value (see the Table) which, in spite of its atypical character, is characterized by moderately weak intensity and short duration. The third group (type III) included 7 events cardinally different from the first group by all three characteristics. The conditions of this cluster are the following: $\mathrm{I}=\left[-0.7 \ldots-1.1^{\circ} \mathrm{C}\right], \mathrm{D}=[5-10$ months], $\mathrm{SO}$ index $=$ $=[0.34-1.43]$. The weakly intensive or mid-enduring La Niña events with low values of the SO index correspond to this type.

Earlier in [2, 3], an attempt was made to classify the La Niña events based on the data series shorter than those in our investigation. The authors, as a rule, examined spatial variability of these events and divided them, by analogy with El Niño, into the Central Pacific and the Eastern Pacific types.

The authors' classification being compared to that obtained in [3] using the 62-year-old array, yields both similarities and differences. The principle of their La Niña classification is based on distinguishing the area of occurrence of the SST cold anomalies using the normalized values of the Nino3 and Nino4 indices and their spatial displacement in the equatorial zone of the Pacific Ocean. Our classification takes into account the index temporal variability in a single region Nino3.4 and does not consider its spatial distribution. It is interesting to note that the La Niña events included in our study in cluster III are not attributed to the Central Pacific type as in [3]. The authors of [2] also used the method of hierarchical cluster analysis, but the values of the sea surface temperature and salinity (SST and SSS) were analyzed as basic parameters. However, their series were even shorter and limited by the period 1977 - 2008. As for the characteristics' spatial variability, the results of our classification are in significant discrepancy with the results of [2]. The matter is that, first, the authors of this paper considered the La Niña event of 1998 - 2000 as two individual events (1998 - 1999 and 1999 - 2000) though proceeding from the Nino3.4 index value, the SST anomaly existed in course of a single continuous non-terminating two-year event. And second, note that using their classification, the authors attributed these two events to two types differing from each other by spatial localization of the maximum anomaly: the La Niña event of 1998 - 1999 was attributed to the Central Pacific type and the La Niña event of 1999 - 2000 - to the East Pacific one. Therefore, taking into account the above-mentioned discrepancies in selecting the La Niña events, it seems incorrect to compare our results with the results obtained in [2].

Analysis of temporal variability of all the La Niña types shown in Fig. 5 indicates presence of a quasi-periodic repeatability. At that it is seen that in the second half of the last century, the La Niña events of type III were observed more regularly. At the same time it is interesting to note that examining, for example, of the first decade of the XX century and that of the present age shows that frequency of the La Niña events' in the XXI century increased. However, if we consider only intensity of the La Niña events of different types, in both cases, i. e. for both 
decades, it is approximately the same. It is difficult to affirm that the abovementioned features are related to the natural low-frequency processes or to the improved quality of the environment monitoring, the role of global warming in this case is also not evident. However, there are some papers, for example [1, 2], in which the authors point out the connection of the inter-annual variability of the El Niño or La Niña events with more low-frequency oscillations in the Pacific oceanatmosphere system, such as the Pacific Decadal Oscillations or the Pacific-North American Oscillations.

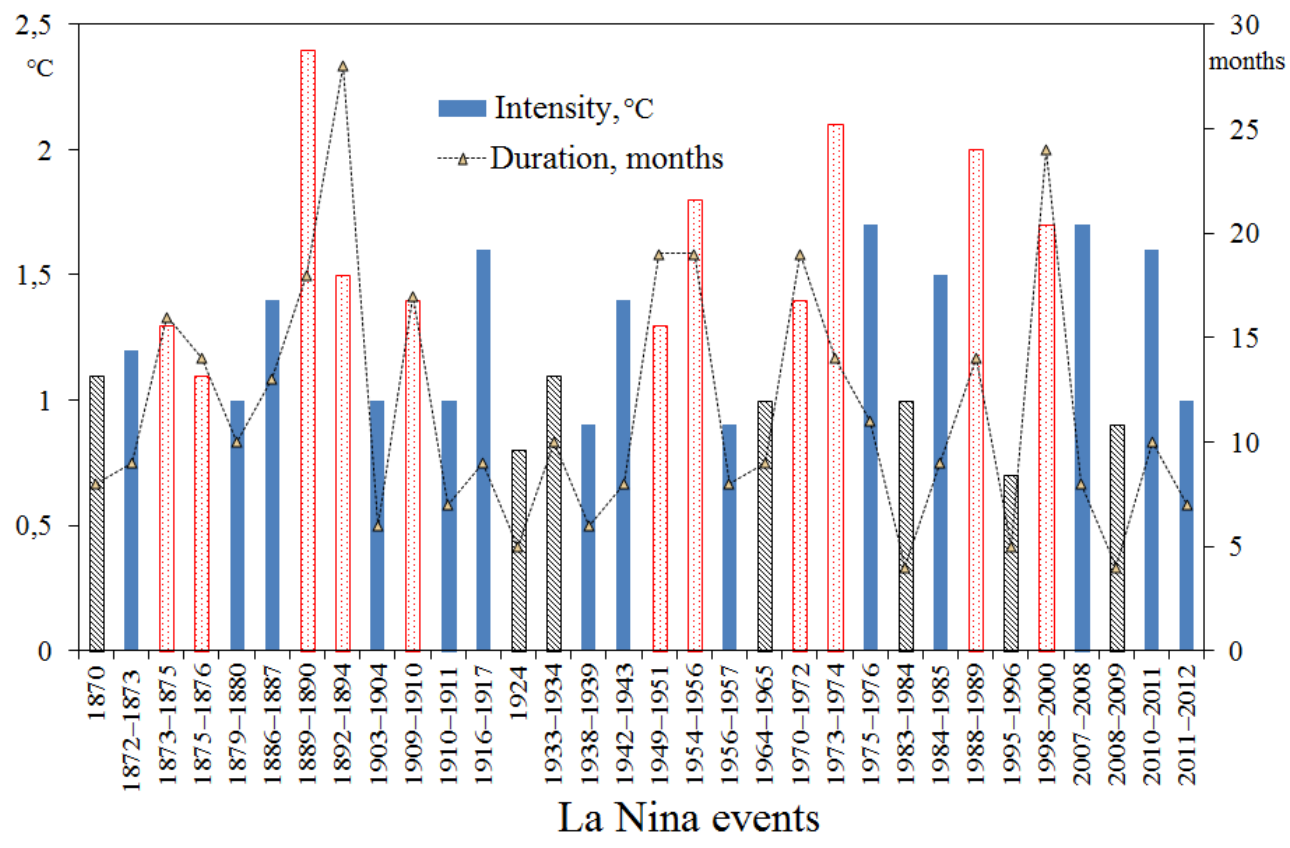

Fig. 5. Histogram of three types of the La Niña events (type I - dotted shading, type II - solid shading, type III - oblique lines) in 1870 - 2013 selected by the method of the cluster analysis using three characteristics; intensity and duration of the events are indicated

Conclusions. Using the HadISST data array for 143 years $(1870$ - 2013) and based on the criterion of the SST anomaly threshold and minimal duration, 32 events of La Niña are distinguished and their statistical characteristics are assessed.

Subjective classification permitted to identify four types of the La Niña events proceeding from their intensity: weak (from -0.7 to $-0.9{ }^{\circ} \mathrm{C}$ ), moderate (from -1.0 to $-1.6^{\circ} \mathrm{C}$ ), strong (from -1.7 to $-1.9^{\circ} \mathrm{C}$ ) and very strong ones $\left(-2.0^{\circ} \mathrm{C}\right.$ and higher), and four types proceeding from their duration: low-enduring ( $4-6$ months), midenduring (7 - 12 months), long-enduring (13 - 23 months) and maximum enduring ones (24 months and more).

Three types of the La Niña events are distinguished by the objective classification using the cluster analysis which allows for the event intensity, duration and the SO index maximum value. Type I (11 events) is characterized by maximum duration (more than two years) and the highest intensity, type II (14 events) - less pronounced features: moderately weak intensity and mid duration, 
and type III (7 events) - low intensity and low- or mid-enduring La Niña events with low values of the SO index.

Quasi-periodicity, apparently, conditioned by low-frequency variability in the ocean-atmosphere system is characteristic of the anomalies' temporal variation corresponding to each of the distinguished types.

The classification carried out in the present paper provides a fairly exhaustive qualitative description of the La Niña phenomenon which takes into account temporal changes of three basic characteristics (the event intensity and duration, and the SO index maximum value). Such an approach is suitable for practical application of the information on this phenomenon.

\section{REFERENCES}

1. McPhaden, M.J., Zebiak, S.E. \& Glantz, M.H., 2006, “ENSO as an integrating concept in Earth science”, Science, vol. 314, no. 5806, pp 1740-1745.

2. Singh, A., Delcroix, T. \& Cravatte, S., 2011, "Contrasting the flavors of El Nino - Southern Oscillation using sea surface salinity observations”, J. Geophys. Res, vol. 116, no. C06016, pp. 0148-0227.

3. Yuan, Y., Yan, H.-M., 2013, “Different types of La Nina events and different responses of the tropical atmosphere”, Chin. Sci. Bull, vol. 58, no. 3, pp. 406-415.

4. Glantz, M.H., 2002, “La Nina and its impacts: facts and speculations”, New York, Unit. Nation. Univ., 313 p.

5. Glantz, M.H., 1998, “A La Nina Summit: A Review of the Causes and Consequences of Cold Events”, Boulder: Environmental and Societal Impacts Group, NCAR, 43 p.

6. Rayner, N.A., Parker, D.E. \& Horton, E.B. [et al.], 2003, “Global analyses of sea surface temperature, sea ice, and night marine air temperature since the late nineteenth century”, $J$. Geophys. Res., vol. 108, no. D14, pp. 4407-4418.

7. Ropelewski, C.F., Jones, P.D., 1978, “An extension of the Tahiti-Darwin Southern Oscillation Index”, Mon. Wea. Rev., vol. 115, no. 9, pp. 2161-2165.

8. Orlov, A.I., 2004, “Nechislovaya statistika [Nonnimerical statistics]”, Moscow, M3-Press, 513 p. (in Russian).

9. Orlov, A.I., 2014, “Matematicheskie metody teorii klassififatsii [Mathematical methods of the classification theory]”, Nauchny zhurnal KubGAU, vol. 07, no. 091, pp. 1-28 (in Russian).

10. Bureeva, N.N., 2007, “Mnogomerny statistichesky analiz s ispol'zovaniem PPP "STATISTIKA" [Multivariate statistical analysis using PPP "STATISTICS]", Uchebnometodichesky material po programme povyshenita kvalifikatsii "Primenenie programmnykh sredst vnauchnykh issledovaniyakh i prepodavanii matematiki i mekhaniki”, Nizhniy Novgorod, Nizhegorodsky gos. univ., 112 p. (in Russian).

11. Trenberth, K.E., 1997, “The definition of El Nino”, Bull. Am. Meteorol. Soc., vol. 78, no. 12, pp. 2771-2777.

12. Kug, J.-S., Jin, F.F. \& An, S.I., 2009, “Two types of El Nino events: Cold tongue El Nino and warm pool El Nino”, J. Clim., vol. 22, no 6., pp. 1499-1515.

13. Voskresenskaya, E.N., Mikhailiva, N.V., 2010, “Klassifikatsiya sobytiy El Nino i pogodnoklimaticheskie anomalii $v$ Chernomorskom regione [Classification of the Niño events and weather-climatic anomalies in the Black Sea region]”, Dop. NAN Ukrainy., no. 3., pp. 124130 (in Russian). 